\title{
Tourism Planning and Design of the proposed system of computer software
}

\author{
Zhaorui Yang \\ School of Management Science, Guizhou University of Finance and Economics, Guiyang, Guizhou 550025, \\ China
}

Keywords: Traveling Tips, computer software, Intelligent, Travel advice system

\begin{abstract}
For the present time being, tourist industry is thriving on fire and compute application software has been more and more widely used in tourist trade. However ,there is not yet such an application software as to offer advice to tourists, employees of travel agencies and senior managers. For that purpose, the author designs an application software for traveling tips. This paper focuses on several basic functions of the software and outlines the background of the research and its significance and describes the objective, the major functions, the overall design , the function module and the implementation technology of this software.
\end{abstract}

\section{Introduction}

In today's world, it is generally accepted a special way of life, this lifestyle to meet their high-level needs, and that is tourism. Tourism is a highly economical and cultural industries, the next few years, the tourism industry will surpass the oil, automotive industry and become the world's largest industry. The authors therefore designed the nation's major tourist area travel advice system (hereinafter referred to as the travel advisories systems) to adapt to this lifestyle. Travel advice system is a systematic, intelligent, personalized, personalized customer service system, and its goal is "customer" as the center, travel advice system makes full use of computer technology, multimedia technology, data warehouse technology and management science technology, change from passive to active-service-service new and modern service mode, the user-friendly, personalized service integration.

However, existing tourist services the system can only provide travel information to tourists, and some traffic profiles, features that are not address the substantive issues for tourists, for tourists in an unfamiliar, giving him information is provided to a person of food material is no way to tell him what to do. He just can't do, just don't talk about eating. For tourists, providing them with a fine travel plan is the best choice, the most perfect service.

\section{Travel advice objectives and main features of the system}

(1) Provide recommendations : travel advice system provides users with the most distinguished and the safety advice, under the same economic circumstances of route optimization recommendations, and travel arrangements, from the time the user has made a travel plans for the user to save valuable time and money.

(2) Information: travel advice system, the user can key people related field or click directly related to the type of scenic spots can be queried.

(3) Introduction to related sites: travel advice system, has made amazing caver for users to enjoy different from other travel system, free text explain. In this system, users need to click on the scenic area you need to know, you can see the real landscape portrait that allows users to "no longer just the sound ", and meet the king. 


\section{Travel advice overall design of the system}

According to the needs of tourists, tourist information users need to be queried. On the tour Swim transportation and accommodation information you need to know, more hope on this basis have a full brigade Tour suggestions. So travel advice system in order to meet the most widespread use of the tourist demand, Special divided into several modules. The specific structure as shown in Fig. 1.

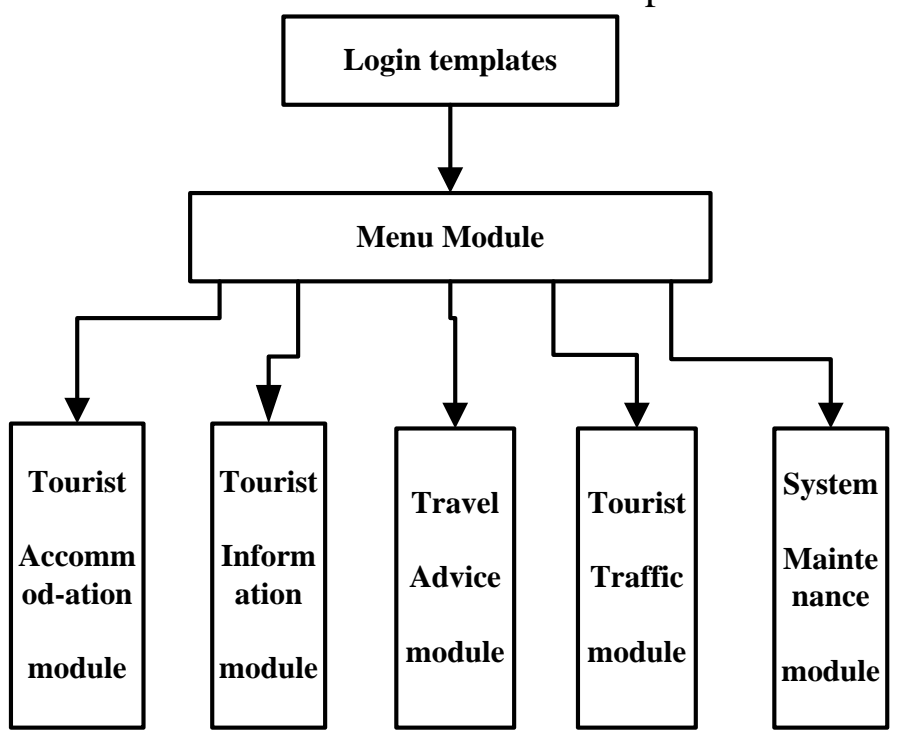

Fig. 1 Travel advice system design

\section{Travel advice system implementation}

Implementation of travel advice key is how to provide advice for users of the system, using prior information stored in databases, when users click on city names on the map, the system will automatically convert the city's name keywords and the system queries and output - related information.

Here's how to implement this functionality. This algorithm by the given predicate logic:

Predicate:

$F(x): x$ is user selected destination; $G(y): y$ is user selected departure

$H(x, y): x, y$ are database query and output-related information

$S(x, y): x, y$ please select again

Reasoning principles:

$$
\begin{aligned}
& \operatorname{ExEy}(F(x) \wedge G(y)) \rightarrow H(x, y) \\
& V x(F(x)) \rightarrow H(x, y) \\
& V x(G(x)) \rightarrow H(x, y)
\end{aligned}
$$

So:

$$
\operatorname{Vx} \operatorname{Vy}(F(x) \vee G(y)) \rightarrow H(x, y) \rightarrow S(x, y)
$$

The user can select different travel costs, based on the needs of a particular play for time, means of transport provided by the system for which a detailed travel advice. According to the different needs of the situation, for each of the charges for package tours, playing time, and transport set of 5 different levels. The following State in charges for package tours, for example specific implementation process.

This algorithm by the given predicate logic:

$P(x): x$ travel costs less than $\$ 500 ; Q(x): x$ travel costs between $\$ 1500$ to $\$ 500$

$W(x): x$ travel costs between $\$ 2,500$ to $\$ 1501 ; Y(x): x$ travel cost more than $\$ 2,500$ 
$S(x): x$ will query the database and give advice; $A(x): x$ is output, please re-enter

$$
\begin{aligned}
& V x(P(x)) \rightarrow S(x) \\
& V x(Q(x)) \rightarrow S(x) \\
& V x(W(x)) \rightarrow S(x) \\
& V x(Y(x)) \rightarrow S(x) \\
& V x(P(x) \vee Q(x) \vee W(x) \vee Y(x)) \rightarrow A(x)
\end{aligned}
$$

\section{Level and type of IT support of the tourist experience}

Tourists generated after receiving information processing travel experience. For example, the reputation of media publicity, corporate advertising, friends and family, or friends, network evaluation, guided tours belong to such information. Such information leading to the formation of expectations of tourists and tourism activities affect the quality of experience. Full of tourists to their senses or direct travel experience gained with the information technology support, this level is by watching, listening, recorded in real terms, including direct access to relevant data and information for tourism, to complete travel experience. For example, Adventure, scientific research and other activities to get this experience, such as Li Bai, Xu Xiake's travel experience also belongs to the level of the ancients

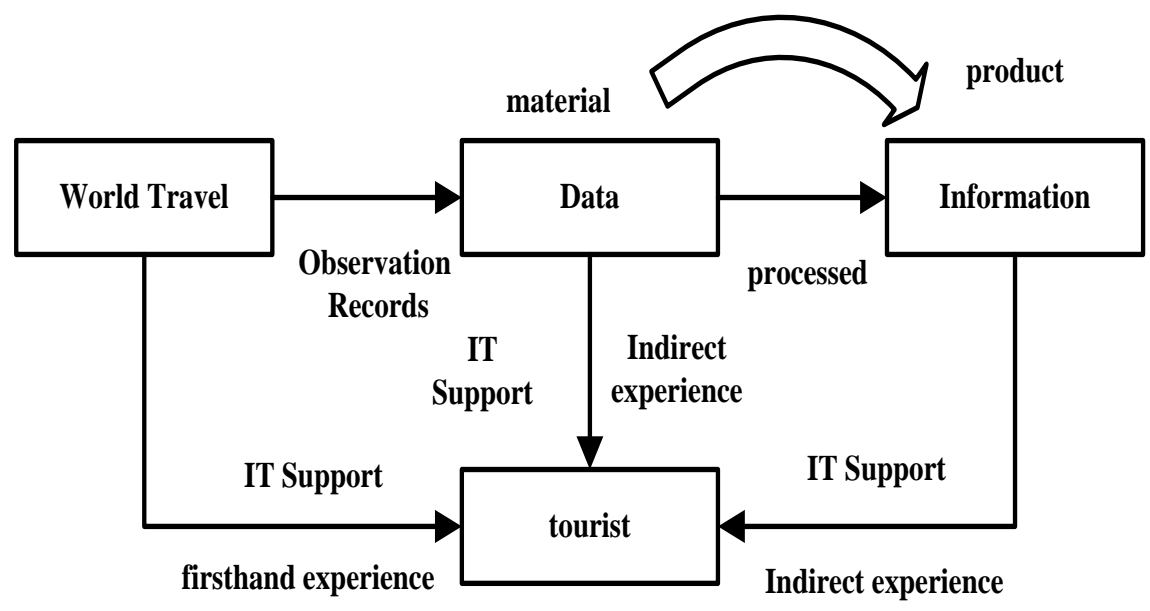

Fig.2 Information on travel experience the road map

To existing knowledge systems, when it is difficult to obtain real-life experience memories, information technology (such as mobile Internet, etc.) to help record real-life experience, preservation and dissemination of real-time. As the access to and dissemination of information more convenient, low-cost, everyone can become a "reporter", "author", "remarks home". Thinker. "Writing and dissemination of information increasingly cheap, so the object of the decision from the tourism travel experience, is turning to construct a positive travel experience for tourists.

\section{Summary}

Travel advice system has been initially perfect, but there are still some problems to be solved: how to implement a system of intelligent, how to use the minimum path generation method to achieve and how to achieve optimal path selection, and so on. For this author is improving the system. 


\section{References}

[1] Ning Wang: Annals of Tourism Research, Vol. 26 (1999) No.2, p.349.

[2] Mark H,Stuart M,Michael Siegel. Data Integration Using Web Services. EEXTT and DIWeb 2002,LNCS 2590,Springer-Verlag Berlin Heidelberg,2003,165-182.

[3] Jon A: International Journal of Service Industry Management, Vol. 11 (2000) No.2, p.120.

[4] Kannan P K Rao H R: Decision Support Sysmms, Vol. 32 (2001) No.2, p.83.

[5] Guarino N, Masolo C, Vetere G Onto Seek: IEEE Intelligent Systems, Vol. 14 (1999) No.3, p.70. 